NBER WORKING PAPER SERIES

TARGET ZONES AND INTEREST RATE VARIABILITY

Lars E.O. Svensson

Working Paper No. 3218

NATIONAL BUREAU OF ECONOMIC RESEARCH

1050 Massachusetts Avenue

Cambridge, MA 02138

December 1989

Part of the work for this paper was done while I was a Visiting Scholar at the Research Department at the International Monetary Fund. I thank the Research Department for its hospitality. I am grateful for discussions with Guiseppe Bertola, Avinash Dixit, Michael Dooley, Bernard Dumas, Robert Flood, Thomas Franzen, Kenneth Froot, Peter Garber, Michael Harrison, Elhanan Helpman, Lars Horngren, Graciela Kaminsky, Maurice Obstfeld, Torsten Persson, Anders Vredin, and Guido Tabelini, and for comments by participants in seminars at IIES, IMF, and the Stockholm School of Economics, and the World Bank. I thank Molly Akerlund for editorial and secretarial assistance, and Cindy Miller for editorial assistance. I also thank John Hassler for research assistance. The project has received partial support from the Bank of Sweden Tercentenary Foundation. Responsibility for remaining errors and obscurities rests with me alone. This paper is part of NBER's research program in International Studies. Any opinions expressed are those of the author not those of the National Bureau of Economic Research. 
NBER Working Paper \#3218

December 1989

\section{TARGET ZONES AND INTEREST RATE VARIABILITY}

\section{ABSTRACT}

The trade-off between interest rate variability and the width of an exchange rate target zone is examined, using the regulated Brownian motion model of target zones. It is shown that for narrow exchange rate bands, and for reasonable parameter values, the interest rate differential's asymptotic variability is increasing in the width of the exchange rate band; whereas for wide exchange rate bands it is slowly decreasing in the exchange rate band. The interest rate differential's instantaneous variability is decreasing in the width of the exchange rate band.

A narrow target zone differs from a completely fixed exchange rate regime in that the interest rate differential's instantaneous standard deviation is high and even increases when the zone narrows.

The model is extended to include a realignment/devaluation risk, as well as an endogenous exchange rate risk premium. The risk premium is small for reasonable parameter values and does not matter much.

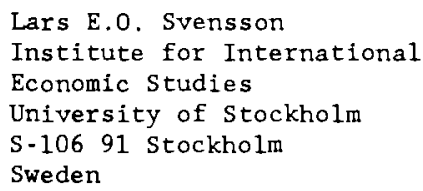




\section{Introduction}

If exchange rate variability is reduced, where does the variability go? If exchange rate variability is reduced all the way to a completely fixed exchange rate regime, the traditional answer is that the variability goes into the money supply, and into price and output levels in more general models. But what about intermediate cases? This paper examines such an intermediate situation where an exchange rate target zone in a small open economy is narrowed, without going all the way to a completely fixed exchange rate regime. In particular, the paper focuses on the extent to which the exchange rate variability goes into interest rate variability during such an experiment. Consequently: the paper examines how the the instantaneous (conditional) as well as asymptotic (unconditional) probability distributions of the interest rate differential and the exchange rate depend on the width of the target zone. ${ }^{1}$

Is a narrow target zone decisively different from a completely fixed exchange rate regime? This paper also attempts to answer that question as well. To some extent, this is in response to Krugman's (1989) provocative suggestions that the theory of fixed exchange rate regimes may need to be reconsidered in terms of very narrow bands rather than completely fixed exchange rates. ${ }^{2}$

The model used is the increasingly popular model of a nominal exchange rate target zone based on regulated Brownian motion. This model was first formulated by Ḱrugman (1988), and has later been extended by Miller and Weller (1988, 1989a, b),

\footnotetext{
1 My interest in this problem was stimulated by illuminating and most helpful discussions with Thomas Franzén and Lars Hörngren, Bank of Sweden, on the possible trade-off between the width of the Swedish exchange rate band and the variability of the Swedish interest rate. (Sweden has a unilateral target zone with a band equal to \pm 1.5 percent around a central exchange rate specified in terms of a trade-weighted basket of foreign currencies, with double weight for the dollar.)

2 Krugman's (1989) conjecture is in the context of understanding speculative attacks on a gold standard. Buiter and Grilli (1989) argue, however, that for the purpose of understanding such speculative attacks there is no need to abandon the assumption of a perfectly fixed exchange rate.
} 
Flood and Garber (1989), Froot and Obstfeld (1989a, b). Klein (1989a, b) and Krugman (1989) ${ }^{3}$ This model allows a convenient derivation of both the instantaneous and asymptotic properties of the exchange rate and the interest rate differential. Nevertheless, the variability of the interest rate differential seems not to have been examined yet. The only exception seems to be an observation by Flood and Garber (1989) (and in an unpublished note from 1988 by Flood) that there will be more variability in the interest rate with a target zone than with either completely fixed exchange rates or a free float.

This paper also extends the target zone model by including an endogenous risk premium, and by incorporating a devaluation risk.

The paper is made up of 10 brief sections. Section 2 restates Krugman's (1988) model for the exchange rate, specifies the exchange rate equation and derives its solution for a free float and a target zone. Section 3 discusses the asymptotic exchange rate distribution. Section 4 derives the interest rate differential, and section 5 discusses its asymptotic variability. Sections 6 and 7 derive the instantaneous variability of the exchange rate and the interest rate differential. Section 7 also briefly discusses whether a narrow target zone is different from a completely fixed exchange rate. Section 8 examines the model with an endogenous risk premium, and section 9 incorporates a devaluation risk. Section 10 summarizes and concludes.

\section{The Exchange Rate}

We use the basic loglinear model of the exchange rate. The log of the exchange rate

3 Dumas (1989a) specifies a two-country general equilibrium model with physical capital movements where the real exchange rate behavior is similar to the nominal exchange rate behavior in the Krugman model.

Solution techniques for problems with regulated Brownian motion are discussed in Harrison (1985), Dixit (1989b) and Dumas (1988b). The latter two papers also give references to the rapidly growing literature in which the techniques of regulated Brownian motion are applied to economic problems other than target zones, notably problems of irreversible investment and hysteresis. 
at time $t, e(t)$, is equal to a 'fundamental,' $f(t)$, plus a term proportional to the expected percentage change in the exchange rate:

$$
\epsilon(t)=f(t)+\alpha E[d e(t)] / d t, \alpha>0,
$$

where $E$ is the expectations operator.

This exchange rate equation can be seen as the result of a simple monetary exchange rate theory for a small open economy. In this case the fundamental is the sum of two components,

$$
f(t)=m(t)+v(t)
$$

(the $\log$ of) the home money supply, $m$, and the (log of the negative of) a composite money demand shock, $v$, called velocity. Velocity is given by

$$
v(t)=-\psi y(t)+q(t)-p^{*}(t)+\alpha i^{*}(t)+\alpha \rho(t)-\epsilon(t) .
$$

Here $\psi$ is the elasticity of money demand with respect to output, $y$ is the log of home output, $q$ is the $\log$ the real exchange rate, $p^{*}$ is the foreign price level, $\alpha$ is (the absolute value of) the semi-elasticity of money demand with respect to the home nominal interest rate, $\imath^{*}$ is the foreign nominal interest rate, $\rho$ is an exogenous risk premium which equals the interest rate differential less the expected exchange rate depreciation, and $\epsilon$ is a money demand disturbance. ${ }^{4}$

In what follows, velocity will be an exogenous stochastic process whereas money supply will be a stochastic process under direct control by a monetary authority. Together these stochastic processes will determine the endogenous stochastic process of the exchange rate via equation (2.1).

The saddle-path solution to (2.1) can be written

$$
e(t)=E_{t} \int_{\tau=t}^{\infty}\{\exp [-(\tau-t) / \alpha] f(\tau) / \alpha\} d \tau
$$

4 The model consists of the money demand function, $m-p=\psi y-\alpha i+\epsilon$, the definition of the real exchange rate, $q=e+p^{*}-p$, and the definition of the risk premium, $p=i$ $i^{*}-E[d e] / d t$. Elimination of $p$ and $i$, assumed to be endogenous and flexible, gives (2.1) (2.3).

See Froot and Obstfeld (1989a) for an interpretation in terms of a two-country model. See also Miller and Weller (1988) for an interpretation in terms of Dornbusch's overshooting model. 
the expected present value of the path of future fundamentals, discounted by $1 / \alpha$, where $E_{t}$ denote expectations conditional upon information available at time $t$. The saddle-path solution excludes bubbles. The expected value of a bubble would grow exponentially in the present model. Since we are going to discuss exchange rates which are restricted to a target zone, it makes particular sense to exclude bubbles. Therefore, we will only discuss saddle-path solutions to (2.1).5 6

\subsection{Free Float}

First we specify what the exchange rate is under a free float. We assume that under a free float the money supply $m$ is held constant at, for simplicity, a zero level,

$$
m=0 \text {. }
$$

Then the fundamental is simply equal to velocity, $f=v$. Velocity and hence the fundamental is assumed to follow a Brownian motion with drift $\mu$ and instantaneous standard deviation $\sigma$,

$$
d v=\mu d t+\sigma d z
$$

where $z$ is a Wiener process with $E[d z]=0$ and $E\left[(d z)^{2}\right]=d t$. This implies that the probability distribution of $f(t)$ at time $t$, conditional upon $f(0)=f_{0}$ at time 0 , is normal with mean $f_{0}+\mu t$ and variance $\sigma^{2} t$. In particular, $E_{t}[f(\tau)]=f(t)+\mu(\tau-t)$ for $\tau \geq t$. By integrating (2.4) we see directly that the solution to the exchange rate equation (2.1)

5 A bubble to (2.1) is a stochastic process $B(t)$ that can be added to the solution (2.4) and produce another solution. Such a bubble must obviously fulfill $B(t)=\alpha E[d B] / d t$, that is, it has an expected growth rate equal to $1 / \alpha$. Any stochastic process of the form $d B_{t}=\left(B_{t} / \alpha\right) d t+\sigma_{t} d z$, where $\sigma_{t}$ could be a function of $B_{t}$, will do. A special case is the deterministic exponential $B_{t}=B_{0} \exp (t / \alpha)$. Since $\alpha>0$ in the present model, the expected value of a bubble would grow indefinitely.

6 The exchange rate equation can also be seen as representing a more general asset pricing equation. The equivalence to a standard asset pricing relationship has been noted by Smith (1989): Set $1 / \alpha=\delta$ and $f(\tau) / \alpha=U_{c}(c(\tau)) D(\tau) / U_{c}(c(t))$. Then the saddle-path solution (2.4) is $e(t)=E_{t} \int_{\tau=t}^{\infty}\left\{\exp [-\delta(\tau-t)] U_{c}(c(\tau)) D(\tau) / U_{c}(c(t))\right\} d \tau$, the usual present value at time $t$ of an asset with dividends $D(\tau)$ in a representative-consumer economy with instantaneous utility $U(c(\tau)$; and discount rate $\delta$. 
is simply

$$
\hat{e}(t)=f(t)+\alpha \mu
$$

\subsection{Target Zone}

Next we model a target zone for the exchange rate. We like to specify a situation where interventions are undertaken by the monetary authority to prevent the exchange rate to move outside a specified exchange rate band. As Flood and Garber (1989) and Froot and Obstfeld (1989a) have emphasized, it is not sufficient to just specify that interventions will occur when the exchange rate reaches the edges of the band. This is because there are several different ways to intervene to defend a given exchange rate band. In order to have a determinate equilibrium it is indeed necessary to specify exactly how the interventions are undertaken.

More precisely, we assume that interventions in the foreign exchange market, which directly affect the money supply, are made to prevent the fundamental from moving outside a specified band for the fundamental. As we shall see this will imply a well-defined band for the exchange rate.

Hence we assume that there are lower and upper bounds for the fundamental, $f$ and $f$, such that the fundamental fulfills

$$
f \leq f(t) \leq f .
$$

With interventions affecting the money supply, the stochastic process for the fundamental obeys

$$
d f=d m+d v
$$

where we now let $d m$ represent the foreign exchange market interventions. Velocity is assumed to follow the Brownian motion $(2.5 \mathrm{~b})$. Inside the band, there are no interventions, $d m=0$, and the fundamental follows

$$
d f=d v=\mu d t+\sigma d z
$$

At the edges of the band, there are infinitesimal interventions to prevent the fundamental 
from moving outside the band. ${ }^{7}$ These interventions can be represented by a lower and an upper 'regulator,' $L$ and $U$, such that

$$
d m=d L-d U
$$

where $d L$ and $d U$ are nonnegative, $d L$ represents increases in money supply and is positive only if $f=f$, and $d U$ represents reductions in money supply and is positive only if $f=f$. Once the fundamental moves inside the band, the interventions cease. This implies that the fundamental is a regulated Brownian motion. 8

In order to find a solution to the differential equation (2.1) under these circumstances, we postulate that the exchange rate will be a sufficiently differentiable function of the fundamental,

$$
e(t)=e(f(t))
$$

Application of Ito's lemma on $e(f)$ to express $E[d e] / d t=E[d e(f)] / d t$ and substitution into (2.1) results in the second-order ordinary differential equation

$$
e(f)=f+\alpha \mu e_{f}(f)+\alpha \sigma^{2} e_{f f}(f) / 2,
$$

where $e_{f}$ and $e_{f f}$ denote the first- and second-order derivatives of $e(f)$. The general solution to this function is given by

$$
e(f)=f+\alpha \mu+A_{1} \exp \left(\lambda_{2} f\right)+A_{2} \exp \left(\lambda_{2} f\right),
$$

where $\lambda_{1}$ and $\lambda_{2}$ are the roots to the characteristic equation in $\lambda$,

$$
\left(\alpha \sigma^{2} / 2\right) \lambda^{2}+\alpha \mu \lambda-1=0 .
$$

The last two terms in (2.13) are obviously the terms by which the target zone exchange rate deviates from the free float exchange rate (2.6). The constants $A_{1}$ and $A_{2}$ in these terms are determined from the much discussed "smooth pasting" conditions,

$$
e_{f}(f)=e_{f}(f)=0
$$

that the function $e(f)$ should be flat at the bounds of the fundamental and, as we shall see, tangent to the edges to the exchange rate band. We shall give some intuition for the

$7 \quad$ Flood and Garber (1989) extend the target zone model to include finite interventions.

8 See Harrison (1985) for the theory of regulated Brownian motion. 
smooth pasting conditions below. 9 The smooth pasting conditions and (2.13) then implies

$$
\begin{gathered}
1+A_{1} \lambda_{1} \exp \left(\lambda_{1} f\right)+A_{2} \lambda_{2} \exp \left(\lambda_{2} f\right)=0 \text { and } \\
1+A_{1} \lambda_{1} \exp \left(\lambda_{1} f\right)+A_{2} \lambda_{2} \exp \left(\lambda_{2} f\right)=0,
\end{gathered}
$$

from which the constants $A_{1}$ and $A_{2}$ can be solved. ${ }^{10}$

The function $e(f)$ thus derived can be shown to be increasing, and the exchange rate will have lower and upper bounds given by

$$
e=e(f) \text { and } \bar{e}=e(f) \text {. }
$$

For the case with zero fundamental drift and a symmetric fundamental band,

$$
\mu=0 \text { and } f=-f \text {, }
$$

there is a neat symmetric solution. Then the roots $\lambda_{1}$ and $\lambda_{2}$ can be written $\lambda_{1}=-\lambda<0$ and $\lambda_{2}=\lambda>0$, where

$$
\lambda=\sqrt{2 / \alpha} / \sigma
$$

The constants $A_{1}$ and $A_{2}$ fulfill $A_{1}=A>0$ and $A_{2}=-\mathrm{A}<0$, with

$$
A=1 /[2 \lambda \cosh (\lambda f)] \text {. }
$$

The target zone exchange rate can then be written as 11

$$
e(f)=f-\sinh (\lambda f) / \lambda \cosh (\lambda f)] .
$$

The now familiar $\mathrm{S}$-shape of the target zone exchange rate, and the straight-line free float rate, are plotted as functions of the fundamental in Figure 1. They are denoted $\epsilon$ and $\hat{e}$, respectively, in the Figure. (Disregard the curve through $Y X Z$ at the moment.) The

9 See Krugman (1988), Dixit (1989b) and Dumas (1988b) for further discussion of the smooth pasting conditions.

10 The general solution (2.13) is also the general solution to the free float case without any bounds on the fundamental. Then the smooth pasting conditions do not apply, and the constants $A_{1}$ and $A_{2}$ must the be determined in some other way. One can then exploit that the roots $\lambda_{1}$ and $\lambda_{2}$ of the characteristic equation have different signs. Let us impose the requirement that the free float exchange rate shall not deviate arbitrarily far from the fundamental, when the fundamental takes arbitrarily large negative or positive values. It follows that the constants $A_{1}$ and $A_{2}$ must both be zero. This provides a. motivation for the simple solution (2.6), which we obtained by directly integrating (2.4).

11 We recall that the hyperbolic sine and cosine fulfill $\sinh (x)=[\exp (x)-\exp (-x)] / 2$ and $\cosh (x)=[\exp (x)+\exp (-x)] / 2$. 
parameters are $\mu=0$, no fundamental drift; $\sigma=.1$, which corresponds to a standard deviation of the exchange rate of 10 percent per year under free float; and $\alpha=3$, which corresponds to a money demand interest rate elasticity of .3 with a 10 percent nomina! interest rate. Unless explicitly stated otherwise, this is the standard set of parameters for which all diagrams will be constructed. The bounds for the fundamental in Figure 1 are \pm 9.4 percent $(f=-f=.094)$, which under zero fundamental drift corresponds to symmetric bounds for the exchange rate equal to \pm 1.5 percent $(\bar{e}=-\underline{e}=.015)$, the width of the Swedish exchange rate band.

We see in Figure 1 that the target zone exchange rate differs considerably from the free float rate, and that it is bent away from the free float rate. The target zone exchange rate function is tangent to the edges of the band, in accordance with the smooth pasting conditions (2.15a). The target zone rate is less responsive to the fundamental than the free float rate,

$$
e_{f}(f)<1
$$

and the band for the target zone rate is less than the band for the fundamental,

$$
\bar{e}<f \text {. }
$$

In order to understand this intuitively, let us start by understanding the smooth pasting conditions. In the zero drift case, we know that the solution can be written $e(f)=f-A[\exp (\lambda f)-\exp (-\lambda f)]$, and it remains to determine the constant $A$. Varying $A$ we get a family of curves in Figure 1, each corresponding to a particular value of $A$. For a zero $A$ we get the free float line, for a negative $A$ we get curves through the origin which are steeper than the free float line, and for a positive, not too large, $A$ we get a curve like the one through the point $X$, that is, a curve through the origin which is flatter than the free float line, concave to the right of the origin, and eventually rises to a maximum and then falls. Consider the curve through $X$, which is rising at the upper edge of the fundamental band. Can that curve be a solution to the target zone exchange rate? We know that the curve fulfills (2.1), so it is a mathematical (although from the argument 
in footnote 10 , not an economically meaningful) solution to the free float case without any fundamental bounds. In the free float case, if the fundamental and the exchange rate are at a level corresponding to $X$, a moment later the fundamental and the exchange rate may have moved to the left, corresponding to $Y$, or to the right, corresponding to $Z$. Since the curve is concave, the corresponding expected change in the exchange rate is negative. That is, the second term on the right hand side in (2.1) is negative, and the exchange rate is less than the fundamental. Now, consider the case with a target zone. If the fundamental and the exchange rate are at $X$, they can still move left to $Y$. If the velocity shocks in the absence of intervention move the fundamental to a level corresponding to $Z$. interventions will reduce the money supply and shift the fundamental back to the upper edge, and the fundamental and exchange rate will stay at $X$. Clearly, the expected exchange rate change associated with either moving to $Y$ or staying at $X$ is more negative than that associated with either moving to $Y$ or moving to $Z$. Hence, the expected exchange rate change is more negative with a target zone and the second term in (2.1) is more negative. Then $X$ cannot be an equilibrium with a target $z o n e$, and the exchange rate must be somewhere vertically below $X$. The curve through $X$ cannot be a solution to the target zone case. The only situation when the same curve can be both the (mathematical) solution to the free float case and the (economic and mathematical) solution to the target zone case is when the curve is horizontal at the upper edge, that is, when the smooth pasting condition holds. A symmetric argument explains why the smooth pasting condition must hold also at the lower edge.

Thus, at the upper edge the exchange rate can only fall or stay constant, and the expected change in the exchange rate is negative, and the exchange rate must be less than the fundamental and the free float rate. Equivalently, expectations of interventions that will reduce the money supply imply that the home currency is expected to appreciate. That the exchange rate is less than the fundamental at the upper edge of the band affects the exchange rate inside the band and makes the exchange rate less than the fundamental 
throughout the upper half of the band (although strictly speaking the expected interventions in the next instant drop to zero in the interior of the band, because of the continuity of Brownian motions). The reverse is true in the lower half of the band, where expectations of a rise in the exchange rate make the exchange rate greater than the fundamental. (A similar argument also holds in the case with nonzero velocity drift when the fundamental and the free float exchange rate differ.)

The exchange rate band is increasing in the fundamental band, as is shown in Figures $2 a$ and $b$, with $\alpha$ ranging from 1 to 5 .

Figure 3 shows the target zone and free float exchange rate band for a much wicier fundamental band, $\pm 100(\log )$ percent, which corresponds to an exchange rate band of \pm 88 (log) percent (which for such large bands corresponds to about +140 and -60 'level' percent). ${ }^{12}$

We note that the target zone exchange rate in this case is approximately equal to the free float exchange rate except at the very edges of the band. We can also easily see this in the special case with zero fundamental drift. For a large symmetric band, we have the approximate relation

$$
e(f) \approx f-[\exp (\lambda f)-\exp (-\lambda f)] /[\lambda \exp (\lambda f)]
$$

since for large $f \cosh (\lambda f) \approx \exp (\lambda f) / 2$. We see that for $f$ far from the edges, the second term on the right-hand side of $(2.21)$ is small relative to the first, that is, $e(f) \approx f$. We also see that at the edge of the band, the exchange rate fulfills $\bar{e} \approx f-1 / \lambda=$ $f-\sigma / \sqrt{2 / \alpha}$.

Intuitively, with a large band the possibility of interventions affects the exchange rate only close to the edges of the band, where interventions can be shortly expected. Away from the edges, any interventions are much more remote in time, the expected change in

\footnotetext{
12 Since the product of the root $\lambda$ and the fundamental enters in (2.18c), and $\lambda$ according to $(2.18 \mathrm{a})$ is inversely proportional to the standard deviation of the fundamental $\sigma$, it is $f$ in relation to $\sigma$ that actually decides whether a band is small or large.
} 
the exchange rate is roughly zero, and the exchange rate coincides with the fundamental and the free float rate.

Finally let us briefly return to the issue of the necessity to specify the band for the fundamental. Above we argued that in order to avoid multiple equilibria it was necessary to specify exactly how the interventions are done, and in particular to explicitly specify the fundamental bounds $f$ and $f$. If only the exchange rate bounds $\underline{e}$ and $\bar{e}$ are announced, there are multiple equilibria, as Flood and Garber (1989) and Froot and Obstfeld (1989) have shown. However, all the examples given of multiple equilibria involve finite as opposed to infinitesimal interventions. Suppose now that the monetary authority announces only the exchange rate band together with the rule that only infinitesimal interventions will be undertaken, perhaps specifying that reductions (increases) in the money supply will only occur when the exchange rate is at its upper (lower) bound, that is, when the currency is weak (strong). It seems that such an announcement could only result in one unique equilibrium, the one we have discussed above, and that the corresponding fundamental bounds can be inferred even though they are not announced.

\section{The Asymptotic Exchange Rate Distribution}

The asymptotic (unconditional) probability distribution of a regulated Brownian motion with both upper and lower bounds is derived in Harrison (1985). With zero drift the asymptotic distribution is uniform; with nonzero drift it is truncated exponential. More precisely, the asymptotic density function $\psi_{(f)}$ for the fundamental is, for $f \leq f \leq f$, given by

$$
\begin{gathered}
\psi(f)=1 /(f-f), \text { for } \mu=0, \text { and } \\
\psi(f)=\theta \exp (\theta f) /[\exp (\theta f)-\exp (\theta f)], \text { for } \mu \neq 0,
\end{gathered}
$$

where $\theta=2 \mu / \sigma^{2}$. 
It follows that the target zone exchange rate has the asymptotic density function

$$
\varphi^{e}(e)=\varphi^{f}\left(e^{-1}(e)\right) / e_{f}\left(e^{-1}(e)\right)
$$

for $\underline{e}<e<\bar{\epsilon}$, where $e^{-1}(\cdot)$ denotes the inverse of $e(f) .{ }^{13}$

Since the density function of the fundamental is exponential or uniform, and the exchange rate is a sum of a linear and exponential terms, it is possible to compute its exact asymptotic mean and variance as a function of the width of the fundamental band. also for nonzero drift of the fundamental.

The density function for the exchange rate is shown in Figures $4 a$ and $b$ for a small and a large band, respectively, and for a zero fundamental drift. (Note that the scale of the figures are different.) The distribution is bimodal, with more mass towards the edges of the band than the uniform distribution. ${ }^{14}$ This is also apparent from the S-shape in Figures 1 and 3 . With the fundamental being uniformly distributed, the S-shape implies that the exchange rate will have more probability mass near the edges of the band than the uniform distribution. The derivative $e_{f}$ in the denominator of (3.2) is smaller close to the edges of the band, making the density larger. Consequently the standard deviation of the exchange rate will exceed the standard deviation of a uniformly distributed random variable with the same band. Figures $5 a$ and $b$ show the asymptotic standard deviation of the exchange rate, std[e], together with the standard deviation, std[u], of a random variable $u$ uniformly distributed on the interval $\underline{e} \leq u \leq \bar{e}$. We see that the exchange rate's asymptotic standard deviation exceeds the uniform random variable's standard deviation by around 15 percent, roughly independent of the size of the band and the semi-elasticity of money demand. This prediction should provide one testable hypothesis of the target zone model.

13 Since the exchange rate function is strictly increasing and invertible only on the interior of the band (recall that its derivative is zero at the edges of the band), the density function for the exchange rate is defined only on the interior of the exchange rate band.

14 Froot and Obstfeld (1989a) concluded in a verbal discussion of the exchange rate's asymptotic distribution that it should be bimodal. 


\section{The Interest Rate Differential}

We assume that there is an exogenous risk premium, $\rho(t)$, that links the interest rate differential and the expected depreciation of the exchange rate, that is,

$$
i(t)=i^{*}(t)+E[d e(t)] / d t+\rho(t) .
$$

In section 8 below we shall examine the case with an endogenous risk premium. For convenience we set here the risk premium equal to zero. Letting $\delta(t)=i(t)-\imath^{*}(t)$ denote the interest rate differential, we then have

$$
\delta(t)=E[d e(t)] / d t
$$

\subsection{Free Float}

Under a free float it follows directly from $(4.2),(2.6)$ and $(2.5 \mathrm{~b})$ that the free float interest rate differential, $\hat{\delta}(t)$, is simply given by the constant drift of the fundamental.

$$
\delta(t)=\mu
$$

\subsection{Target Zone}

Under a target zone, we know that the exchange rate is given by the function $e(f)$. We can then directly see from (4.2) and (2.1) that the interest rate differential will simply be given by

$$
\delta(f)=[e(f)-f] / \alpha
$$

the difference between the target zone exchange rate and the fundamental divided by $\alpha{ }^{15}$

It follows from (4.4) that the derivatives of the exchange rate and the interest rate differential are related according to

$$
\delta_{f}=\left(e_{f}-1\right) / \alpha
$$

Since the exchange rate is less responsive to the fundamental than the free float exchange

15 The interest differential by Ito's lemma of course also fulfills $\delta=\mu e_{f}+\sigma^{2} e_{f f} / 2$, but by (2.12) this is identical to (4.4). 
rate $\left(e_{f}<1\right)$, if follows that the interest rate differential will be decreasing in the fundamental.

$$
\delta_{f}<0
$$

It follows that the interest rate differential will move within a band, with lower and upper bounds given by

$$
\underline{\delta}=\delta(f) \text { and } \delta=\delta(f)
$$

It follows from (4.4) and (2.13) that the target zone interest rate differential rate can be written

$$
\delta(f)=\mu+\left[A_{1} \exp \left(\lambda_{1} f\right)+A_{2} \exp \left(\lambda_{2} f\right)\right] / \alpha .
$$

In the case with zero fundamental drift and a symmetric fundamental band, the interest rate differential is given by

$$
\delta(f)=-\sinh (\lambda f) /[\alpha \lambda \cosh (\lambda f)] .
$$

Figure $6 a$ shows the interest rate differential together with the target zone exchange rate and the free float rate, for a small band. It is easy to see that the interest rate differential is the difference between the target zone exchange rate and the fundamental, divided by $\alpha$ which here is equal to 3 . As we noted in the discussion of Figure 1 , in the upper half of the fundamental band the exchange rate is expected to fall, and hence the interest rate differential is negative. The reverse is the case in the lower half of the band, and in the middle of the band the interest rate differential is zero.

Figure $6 b$ blows up the interest rate differential and the target zone exchange rate. We note that for this small band, the interest rate differential appears to be approximately linear in the fundamental, whereas the exchange rate, as we have noted above, appears to be rather non-linear in the fundamental. This circumstance will be important in order for the results of the interest rate differential's variability to follow, so we should make sure that we understand it correctly. Let us, therefore, consider the case with no fundamental drift and a symmetric fundamental band:

The derivative of the exchange rate $(2.18 \mathrm{c})$ will be 


$$
e_{f}=1-[\exp (\lambda f)+\exp (-\lambda f)] /[\exp (\lambda f)+\exp (-\lambda f)]
$$

For a small band, the second term on the right-hand side is less than one, but close to one. This means that $e_{f}$ is positive, but small and much less than one. Then, it follows from (4.5) that the derivative $\delta_{f}$ is approximately constant and given by

$$
\delta_{f} \approx-1 / \alpha
$$

The interest rate differential's responsiveness to the fundamental is almost constant. That is why the interest rate differential appears approximately linear for a small band.

Figure $7 a$ shows the three variables for a large band. In Figure $7 b$ the interest rate differential is blown up. We see that here the interest rate differential, rather than the target zone exchange rate, appears to be rather non-linear in the fundamental, whereas the target zone rate appears to be approximately linear. This again can be understood from (4.10). With a large band, the second term on the right-hand side of (4.10) is small. except at the edges of the band. Therefore, for most of the band the derivative $e_{f}$ is approximately equal to unity, and therefore, by (4.5) the derivative $\delta_{f}$ is approximately zero. Towards the edge of the band, the derivative $e_{f}$ falls to zero, and the derivative $\delta$, falls to $-1 / \alpha$.

Intuitively, for a large band the expected change in the exchange rate and hence the interest rate differential is about zero and almost constant for the middle part of the band, except near the edges where shortly expected interventions make the expected change negative at the upper edge, and positive at the lower edge. The responsiveness of the interest to the fundamental is therefore about zero except near the edges. That is why the interest rate differential appears to be more nonlinear for a large band.

The interest rate differential band is increasing in the fundamental band, as is shown in Figure 8. The interest rate differential bands are themselves bounded. From (4.9) we can see that the interest rate differential bounds are bounded by $1 /(\alpha \lambda)=\sigma / \sqrt{2 \alpha}$. For smaller values of $\alpha$, the semi-elasticity of money demand with respect to the nominal interest rate, the interest rate differential band is wider. We note that for small bands the 
interest rate differential's band is relatively large. For the Swedish exchange rate band of \pm 1.5 percent, the interest rate differential's band is almost \pm 3 percent.

In conclusion, a band on the fundamental gives rise to both an exchange rate band and an interest rate differential band. Interventions occur only when the fundamental reaches the edges of its band, which coincides with the exchange rate and the interest rate differential reaching the edges of their band. The interventions that prevent the fundamental and the exchange rate from moving outside their bands at the same time prevent the interest rate differential from moving outside its band. An exchange rate target zone as we have described it is, therefore, equivalent to an interest rate differential target zone. Defending the exchange rate at the edges of its band is here the same thing as defending the interest rate differential at the edges of its band.

\section{The Asvmptotic Interest Rate Differential Distribution}

Given the interest rate differential function $\delta(f)$ and the asymptotic density function

$f(f)$ of the fundamental, it follows that the interest rate differential has the asymptotic density function

$$
\varphi^{\delta}(\delta)=\varphi^{f}\left(\delta^{-1}(\delta)\right) / \delta_{f}\left(\delta^{-1}(\delta)\right),
$$

for $\delta \leq \delta \leq \delta$, where $\delta^{-1}(\cdot)$ denotes the inverse of $\delta(f) .{ }^{16}$ The asymptotic mean and variance of the interest rate differential can be computed exactly.

The density function is plotted in Figure $9 a$ for different fundamental bands. The fundamental bands are $\pm 6.3, \pm 9.4, \pm 11, \pm 21$, and $\pm 50(\log )$ percent, which (for $\alpha$ equal to 3 ) corresponds to exchange rate bands equal to $\pm .5, \pm 1.5$ (Sweden), \pm 2.25 (EMS except Italy), \pm 10 , and $\pm 38(\log )$ percent. For small bands, the density function is nearly uniform, which is consistent with the interest rate differential's responsiveness to the uniformly

16 Since the interest rate differential is strictly decreasing in the fundamental, it is invertible. 
distributed fundamental being approximately constant (cf. (4.11) and Figure 6b). For larger fundamental bands, the interest band is larger, but the interest rate differential's probability mass is concentrated more around the mean and the density function is more peaked. This is consistent with the interest rate differential being about zero for the middle portion of a large band, and hence its being unresponsive to the fundamental except towards the edges of the band. (The figure does not show the density function for the \pm 100 percent fundamental band since the density function is then too peaked to fit the scale of the figure.)

It follows that the asymptotic variability of the interest rate differential will be increasing in the fundamental band for small bands, but decreasing for large bands. This result is shown in Figure $9 b$, which plots the asymptotic standard deviation of the interest rate differential against the fundamental band, for different values of the semi-elasticity of money. A zero band implies a completely fixed exchange rate, a zero interest rate differential, and zero variability of the interest rate differential. A very large band is similar to a free float, which gives a constant interest rate differential equal to the constant drift of the fundamental and again a zero variability. In between there is positive variability of the interest rate differential.

Figures $10 a$ and $10 b$ plot the asymptotic standard deviation against the exchange rate bounds. We can see in Figure 10a that for the Swedish band, \pm 1.5 percent, for a wide range of semi-elasticities of money demand the standard deviation increases in the band. We can also see in Figure 10b that for semi-elasticities around 3 and above, the standard deviation becomes rather flat for bands between \pm 5 and \pm 15 percent, and then decreases very slowly for larger bands.

\section{Instantaneous Exchange Rate Variability}

Having discussed the asymptotic (unconditional) variability of the exchange rate and 
the interest rate differential, we will now go on to the instantaneous (conditional) variability of the two variables. We start with the exchange rate.

Since the exchange rate is a function $e(f)$ of the fundamental, it will be an Ito process

$$
d e=\mu^{e}(f) d t+\sigma^{e}(f) d z
$$

with drift $\mu^{e}(f)$ and instantaneous standard deviation $\sigma^{e}(f)$ that both depend on the fundamental. The drift is from (4.2) ident:cal to the interest rate differential,

$$
\mu^{e}(f)=\delta(f) \text {. }
$$

The instantaneous standard deviation is by Ito's lemma simply the product of the derivative $e_{f}$ and the instantaneous standard deviation of the fundamental

$$
\sigma^{e}(f)=e_{f}(f) \sigma
$$

Figure 11 plots the instantaneous standard deviation against the fundamental, for different fundamental bands. We note that the instantaneous standard deviation decreases to zero at the edges of the bands. This is consistent with the exchange rate's responsiveness to the fundamental decreasing towards the edges of the band, as shown in Figure 1 and discussed above.

We can also see in Figure 11 that for each level of the fundamental, the instantaneous standard deviation is increasing in the fundamental band. This reflects that the exchange rate becomes increasingly responsive to the fundamental when the band increases. When there is no fundamental drift, we can see in (4.10) that $e_{f}$, for each $f$, is increasing in the fundamental bound $f$.

In sum, the exchange rate is a stochastic process which is both nonlinear, having a variable drift, and heteroscedastic, having a variable instantaneous standard deviation. Dumas (1989a) thoroughly analyzes a somewhat similar stochastic process for the real exchange rate, derived in a real two-country general equilibrium model with physical capital mobility under hysteresis. That real exchange rate process is also nonlinear and heteroscedastic, and Dumas shows that the process implies persistent deviations from the law of one price. 


\section{Instantaneous Interest Rate Differential Variability}

The interest rate differential will be an Ito process

$$
d \delta=\mu^{\delta}(f) d t-\sigma^{\delta}(f) d z
$$

with drift $\mu^{\delta}(f)$ and instantaneous standard deviation $\sigma^{\delta}(f)$ that both depend on the fundamental (since the interest rate differential is decreasing in the fundamental, we write the second term on the right-hand side of (7.1) with a negative sign in order to make sure that $\sigma^{\delta}(f)$ is positive).

In order to find the interest rate differential's drift we note that by (4.4) $d \delta=(d e-d f) / \alpha$. Taking expected values, and using (6.2) and (2.5b), gives

$$
\mu^{\delta}(f)=[\delta(f)-\mu] / \alpha
$$

The instantaneous standard deviation is the product of the negative of the derivative $\delta_{f}$ and the standard deviation of the fundamental,

$$
\sigma^{\delta}(f)=-\delta_{f}(f) \sigma
$$

Using (4.5) and (6.3), we can then write

$$
\sigma^{e}(f)+\alpha \sigma^{\delta}(f)=\sigma
$$

The exchange rate's instantaneous standard deviation and $\alpha$ times the interest rate differential's instantaneous standard deviation sum to the fundamental's instantaneous standard deviation. Hence, there is a linear negative trade-off between the exchange rate's and the interest rate differential's instantaneous variability, in contrast to the non-monotonic relation between the the two variables' asymptotic variabilities.

We can easily understand this by substituting $\delta=E[d e] / d t$ into the exchange rate equation (2.1) and writing the latter as

$$
e(f)-\alpha \delta(f)=f
$$

Since the exchange rate and the interest rate differential are perfectly negatively 
correlated, (7.4) follows. ${ }^{17}$

Figure $12 a$ plots the interest rate differential's instantaneous standard deviation against the fundamental, for different levels of the fundamental band. Because of (7.4), the figure is simply the mirror image of Figure 11. When the instantaneous standard deviation of the exchange rate is large, the instantaneous standard deviation of the interest rate differential is small, and the other way around. For a given level of the fundamental the interest rate differential's instantaneous standard deviation is decreasing in the size of the band, since the exchange rate's instantaneous standard deviation is increasing.

We also see that for a small band the interest rate differential's instantaneous standard deviation is large throughout its band. This is consistent with the interest rate differential's responsiveness to the fundamental being large and almost constant (cf. (4.11) and Figure 6b). For a large band, the instantaneous standard deviation is close to zero, except towards the edges of the band where it rises rapidly. This is consistent with the interest rate differential's responsiveness to the fundamental being close to zero except at the edges of the band (cf. Figure $7 \mathrm{~b}$ ).

The interest rate differential's instantaneous standard deviation will also be decreasing in the band for each level of the interest rate differential, as shown in Figure $12 b$.

Let us finally consider the limit when the fundamental band approach zero. Then the exchange rate, the interest rate differential, and the derivative of the exchange rate also approach zero. The derivative of the interest rate differential, however, approaches the finite limit $-1 / \alpha$.

It follows that the exchange rate's drift and the instantaneous standard deviation, and

17 The variance of the left-hand side of (7.4) is $\left(\sigma^{e}\right)^{2}+\alpha\left(\sigma^{\delta}\right)^{2}-2 \alpha \operatorname{Cov}(e, \delta)=$ $\left(\sigma^{e}+\alpha \sigma^{\delta}\right)^{2}$, where we use that $\operatorname{Cov}(e, \delta)=-\sigma^{e} \sigma^{\delta}$, since $e$ and $\delta$ are perfectly negatively correlated. 
the interest rate differential's drift, all approach zero. In contrast, the interest rate differential's instantaneous standard deviation increases, and approaches the finite limit $\sigma / \alpha$, the fundamental's instantaneous standard deviation divided by the semi-elasticity of the money demand with respect to the interest rate.

It follows that the limit of a narrow target zone differs from an idealized completely fixed exchange rate regime, since in the latter the interest rate differential would have zero instantaneous standard deviation. However, although the interest rate differential's instantaneous standard deviation approaches its supremum, the time intervals the interest rate differential spends between hitting the edges of its band becomes arbitrarily short. Therefore, the relevance of the instantaneous standard deviation is reduced, and any nominal bond with a finite rather than instantaneous maturity will have the standard deviation of its interest rate differential approach zero.

Therefore, we should be careful in interpreting the result about the limit. It does hardly imply that a target zone with an arbitrarily small band is in any relevant sense different from a completely fixed exchange rate regime. What it does imply, I believe, is that realistically narrow target zones, say with an order of magnitude about \pm 1 percent, may very well behave quite differently from an idealized completely fixed exchange rate regime. Indeed, real world fixed exchange rate regimes have in practice been target zones, although possibly with rather narrow bands. As discussed in Yeager (1976, p. 19-21)), even the gold standard had gold points, with a band in between. (The example given by Yeager is actually a band of \pm 1 percent.) The conventional analysis of a fixed exchange rate regime may indeed, for some problems, have to be reconsidered in terms of explicit target zones.

\section{An Endogenous Risk Premium}

So far the risk premium $\rho$ in (2.3) and (4.1) has been taken as exogenous and for 
simplicity even set equal to zero. In this section we shall examine the target zone model with an endogenous risk premium. We shall see, however, that the incorporation of an endogenous risk premium does hardly effect the results we have derived, since the risk premium for reasonable parameter values will be so small as to matter very little.

First, let us redefine velocity (2.3) as not including the risk premium, so that we have

$$
v(t)=-\psi y(t)+q\left(t_{i}-p^{*}(t)+\alpha i^{*}(t)-\epsilon(t),\right.
$$

instead of (2.3). We then write the exchange rate equation as

$$
e(t)=f(t)+\alpha E[d e(t)] / d t+\alpha \rho, \alpha>0,
$$

instead of (2.1).

Next, we would like to determine the risk premium endogenously. This can be dono in a variety of ways. We actually only need to establish a bound on the risk premium and show that the bound is sufficiently small. Let us, therefore, choose a very simple set up. Suppose there are only two assets (aside from money), namely short term domestic and foreign bonds, paying instantaneous nominal interest rates, $i$ and $i^{*}$. Let us take the foreign nominal interest rate, $\imath^{*}$, the foreign price level, $p^{*}$, and the real exchange rate, $q^{*}$. to be deterministic and even constant. Then the foreign bond has a riskless instantaneous rate of return. The risk premium, fulfilling

$$
\rho=i+E[d e] / d t-i^{*}
$$

is consequently the domestic bond's expected instantaneous excess real rate of return return over the riskless rate. Furthermore, the variance of the instantaneous real rate of return on the domestic bond is simply the instantaneous variance of the exchange rate, $\left(\sigma^{e}\right)^{2}$. Let $w$ denote the share of domestic bonds in a representative agent's portfolio, and let $\gamma>0$ denote the representative agent's relative risk aversion. Then the simplest portfolio theory says that the portfolio share of domestic bonds fulfills

$$
w=\rho /\left[\gamma\left(\sigma^{e}\right)^{2}\right] .
$$

It follows that the risk premium fulfills

$$
\rho=\beta\left(\sigma^{e}\right)^{2}=\beta \sigma^{2} e_{f}^{2}, \text { where }
$$




$$
\beta=\gamma w .
$$

The first equality in (8.5a) states that the risk premium will be proportional to the instantaneous variance of the exchange rate. The second equality, where we have exploited $\sigma^{e}=e_{f} \sigma$, states that the risk premium will be proportional to the product of the instantaneous variance of the fundamental and the square of the first derivative of the exchange rate. The factor $\beta$ includes a portfolio share and may be a somewhat complicated function of accumulated interventions.

Let us for a moment contemplate what the differential equation for the exchange rate will be. Using Ito's lemma on $E[d e] / d t$ and substituting (8.5a) in (8.2), the differential equation that needs to be solved is

$$
\epsilon(f)=f+\alpha \mu e_{f}(f)+\alpha \sigma^{2} e_{f f}(f) / 2+\alpha \beta \sigma^{2} e_{f}^{2},
$$

together with the smooth pasting conditions. This differential equation does not look too promising. The term that has been added includes the square of a first derivative, so the equation is no longer linear. Furthermore, as mentioned the foctor $\beta$ is possibly a function of previous interventions. For constant $\beta$, or for $\beta$ given as a function of the fundamental, the differential equation is easy to solve numerically, however. Indeed, if a constant bound for $\beta$ can be found, the equation can be solved numerically for that constant bound, which should give an upper bound of the error from disregarding the risk premium.

Let us next try to construct a bound on the risk premium. The portfolio share of home bonds $w$ is bounded by unity if short sales of foreign bonds are not allowed. With additional assets besides bonds the share is likely to be less. In a more elaborate portfolio problem with other assets, where none of the bonds are riskless, and where the dependence of the exchange rate variability on the fundamental is taken into account (cf. Adler and Dumas (1983) and Ingersoll (1987)) the total portfolio share of domestic bonds is given by the sum of the so-called tangency portfolio, corresponding to the right-hand side of (8.4). and so-called inflation-hedge and state-variable-hedge portfolios. In Frankel's (1982) variant of CAPM the tangency portfolio share is equal to the difference between the total 
portfolio share of domestic bonds and the consumption share of domestic goods, which is equal to the negative of the difference between the portfolio share of foreign bonds and the consumption share of foreign goods. Let us now accept .5 as a generous upper bound of that difference, that is, $|w| \leq .5$. Let us choose a risk aversion coefficient equal to two, $\gamma=2$. It follows that $\beta$ is bounded by unity,

$$
|\beta| \leq 1 \text {. }
$$

Then by ( $8.5 \mathrm{a}$ ) the risk premium is simply bounded by the instantaneous standard deviation of the exchange rate. In the free float case, with our standard set of parameters, the risk premium will be bounded by 1 percent. This is roughly consistent with empirical estimates (cf. Dooley and Isard (1983) and Frenkel (1982, 1986, 1988)).18

In a target zone the responsiveness of the target zone exchange rate to the fundamental is bounded by unity. It decreases to zero at the edges of the band. Hence, for large bands the risk premium would be bounded by 1 percent in the middle of the band, and it would fall to zero towards the edges of the band. For small band, the exchange rate's responsiveness is much less. For the Swedish band of \pm 1.5 percent the responsiveness is bounded by .24 , its square bounded by .058 . Then the risk premium is bounded by only .058 percent in the middle of the band, and falls towards zero at the edges of the band. These numbers are sufficiently small for the risk premium not to have any significant effect on the exchange rate function for both small and large bands, as the

18 Dooley and Isard (1983), using a portfolio-balance approach, report a risk premium of about 2.5 percent per year, but warn that their method may overestimate the risk premium. Frankel $(1982,1986,1988)$, using a mean-variance approach, estimate variancecovariance matrices which, with relative risk aversion equal to two, imply risk premia about 1 percent per year for six major currencies.

The assumptions made in deriving (8.4) imply that foreign bonds are riskless and domestic bonds risky, in real terms. This implies a bias towards a positive risk premium, but that does not matter since we only aim at establishing a bound for the absolute value of the risk premium. A direct use of the basic CAPM makes the risk premium equal the product of the excess return on the market portfolio and the 'exchange rate beta,' the ratio of the covariance between the exchange rate and the rate of return on the market portfolio to the variance of the rate of return on the market portfolio. Many different assets in the market portfolio would seem to generally lead to lower risk premia than the one derived via (8.4). Hodrick (1987) and Hörngren and Vredin (1988b) survey different models for the risk premium. 
numerical solution of (8.6) has indeed confirmed. For large bands, however, the risk premium in the middle of the band is significant relative to the interest rate differential. For small bands, the risk premium is small also relative to the interest rate differential.

Consequently, we find that setting the risk premium equal to zero results in very small relative errors for the exchange rate function regardless of the size of the band. For small bands it also results in small errors for the interest rate differential. 19

\section{Devaluation Risk}

The target zone model presented here predicts relatively small interest rate differentials for small bands. Actual interest rate differentials have often been larger, also during periods of relatively free capital movements (for data for the EMS, see Giavazzi and Giovannini (1989); for data for Sweden, see Hörngren and Vredin (1988a)). It seems likely that such high interest rate differentials may largely be explained by risks of realignments and devaluations. Let us examine this possibility by extending the model 1,0 include the possibility of devaluations.

A devaluation can, of course, be seen as a special kind of regime shift. Several such regime shifts have been studied in the literature using regulated Brownian motion. Krugman (1988) has examined a once and for all shift from a target zone to a free float. which occurs with a given probability once the exchange rate reaches the edge of its band. Miller and Weller (1989a) have studied reoccurring given realignments which occur with some probability when the exchange rate reaches one edge of its band. Froot and Obstfeld (1989a) have studied a once-and-for-all peg of the exchange rate once it reaches a given level, and a once-and-for-all unification of dual exchange rates once the fundamental

19 In Dumas (1989a) real model, an elegant expression for a real risk premium, defined as the difference between the foreign and domestic real interest rates, is derived. That risk premium behaves differently from the nominal risk premium here, being zero on the midpoint of the band as well as at the edges of the band. 
reaches a given level. Krugman (1989) discusses once-and-for-all collapses of target zones regime with limited reserves, including a target zone on a gold standard.

Here we choose to model devaluations as reoccurring with some given constant probability, regardless of where in the band the exchange rate lies. This will allow a simple analytic solution of the exchange rate equation. Also, some real world realignments and devaluations seem indeed to occur when the exchange rate is in the interior of the band. ${ }^{20}$ More precisely we model devaluations as occurring according to a Poisson process $q(t)$ with constant parameter $\nu>0$, meaning that during the interval $d t$ the process will take a jump of unity with probability $\nu d t$ and remain unchanged with probability $(1-\nu d t)$. Then $q(t)$, taking integer values, can be interpreted as the number of devaluations that lave occurred up to and including time $t$.

The details of a devaluation in the present framework can obviously be modeled in several different ways. Generally, in this framework we would associate a devaluation with an announcement of a shift in the band. (We recall that the regime must be specified in terms of a band for the fundamental rather than only a band for the exchange rate, in order to ensure a unique equilibrium.) But we must also specify what interventions are undertaken at the time of the announcement, at least when the old level of the fundamental is outside the new fundamental band. Then the fundamental can be moved either to the edge or the new band, or to somewhere inside the new band.

It turns out to be very convenient to model a devaluation as a simultaneous shift of the same magnitude $g$ in the lower and upper bounds for the fundamental as well as in the money supply. Then a devaluation maintains the fundamental's position relative to the fundarnental band. More precisely, the lower and upper bounds for the fundamental are functions $f(q)$ and $f(q)$ of the number of devaluations given by

$$
f(q)=f_{0}+g q \text { and } f(q)=f_{0}+g q
$$

20 For instance, when Sweden devalued in Sweden in September 1981 and October 1982 the Krona's value was above previous minimum values. 
where $f_{0}$ and $f_{0}$ are constants. After $q$ devaluations, the fundamental is restricted to fulfill

$$
f(q) \leq f \leq f(q)
$$

The upper and lower bounds thus change according to

$$
d f=g d q \text { and } d f=g d q
$$

where $d q$ is unity with probability $\nu d t$ and zero with probability $(1-\nu d t)$.

Similarly, the money supply is now given by the process $m=L-U+g q$, that is,

$$
d m=d L-d U+g d q,
$$

where $L$ and $U$ are the lower and upper regulators referred to in section 2.2 .

A positive $g$ corresponds to devaluations, a negative to revaluations. Let us think of $g$ as positive and continue to refer to devaluations.

The exchange rate still fulfills the exchange rate equation (2.1) (we continue to disregard the risk premium), but it will now be a function $e(f, q)$ of both the fundamental and the number of devaluations. Ito's lemma applied on $e(f, q)$ gives the expected change in the exchange rate as

$$
E[d e(f, q)]=(1-\nu d t)\left[\mu e_{f}(f, q)+\sigma^{2} e_{f f}(f, q) / 2\right] d t+\nu d t[e(f+g, q+1)-e(f, q)] .
$$

The first term on the right-hand side is the usual second-order expression, multiplied by the probability that no devaluation occurs during the interval $d t$. The second term on the right-hand side is the probability that a devaluation occurs times the total jump in the exchange rate due to both the jump of $g$ in the fundamental (due to the jump in the money supply) and the jump of unity in $q$, the number of devaluations.

Due to the symmetry of the setup, with a devaluation being the same jump $g$ in both the fundamental and its lower and upper bounds, we may postulate that the resulting jump in the exchange rate is also equal to $g$, that is,

$$
e(f+g, q+1)-e(f, q)=g .
$$

Using (9.6), ignoring terms of order $d t^{2}$ in (9.5), and substituting into (2.1), we get 
the differential equation

$$
e(f, q)=f+\alpha \nu g+\alpha \mu e_{f}(f, q)+\alpha \sigma^{2} e_{f f}(f, q) .
$$

The smooth pasting conditions will now be

$$
e_{f}(f(q), q)=e_{f}(f(q), q)=0 .
$$

It is not difficult to find the solution to $(9.8)$ and (9.9). It is

$$
e(f, q)=f+\alpha \mu+\alpha \nu g+A_{1} \exp \left[\lambda_{1}(f-g q)\right]+A_{2} \exp \left[\lambda_{2}(f-g q)\right],
$$

where $\lambda_{1}$ and $\lambda_{2}$ are the roots of the characteristic equation (2.14) and the constants $A_{1}$ and $A_{2}$ are given by (2.15) with $f_{0}$ and $f_{0}$ substituted for $f$ and $f$. The solution obviously fulfills (9.6).

Comparing (9.10) for $q=0$ with the solution without devaluation risk, (2.13). we realize that the only modification of the exchange rate function is the addition of the term $\alpha \nu g, \alpha$ times the rate of expected devaluation. In Figure 6a, for instance, the only modification is that the curve corresponding to the target zone exchange rate is shifted up) by $\alpha \nu g$. When a devaluation occurs, the curve is each time shifted up and to the right by the magnitude $g$, hence every point on the curve is shifted on a 45 degree line northeast in the figure.

Ignoring the risk premium, the interest rate differential is given by $(4.2)$ and $(4.4)$. that is,

$$
\begin{aligned}
\delta(f, q) & =(e(f, q)-f) / \alpha= \\
& =\mu+\nu g+\left\{A_{1} \exp \left[\lambda_{1}(f-g q)\right]+A_{2} \exp \left[\lambda_{2}(f-g q)\right]\right\} / \alpha,
\end{aligned}
$$

where the second equality follows from (9.10). We see from (9.11) that the interest rate differential only depends on where the fundamental is relative to its lower and upper bounds, and not on the number of devaluations. Comparing (9.11) for $q=0$ with the case without devaluation risk, (4.8), we see that the only modification of the interest rate differential is the addition of the term $\nu g$, the rate of expected devaluations. In terms of Figure $6 \mathrm{a}$, the curve corresponding to the interest rate differential is just shifted up by $\nu g$. When a devaluation occurs, the curve is shifted to the right by $g$. A devaluation does not 
change the interest rate differential, since the probability of new devaluations by assumptions remains the same.

In conclusion, with this simple way of modeling a devaluation risk, the only consequence for the interest rate differential and the exchange rate is that the constant expected rate of devaluation is added to the former, and the product of that rate and the interest semi-elasticity of money demand is added to the latter. Hence, a nonzero rate of expected devaluation shows up directly in the interest rate differential and can contribute to explaining why the interest rate differential can sometimes be large for small bands and free mobility of capital as well.

\section{Summary and Conclusions}

We have seen that for small exchange rate bands the interest rate differential's asymptotic variability is increasing in the width of the band. For large bands, the interest rate differential's asymptotic variability is slowly decreasing in width of the band. The interest rate differential's instantaneous variability is always decreasing in the width of the band.

The target zone model as presented results in rather complicated stochastic processes for the exchange rate and the interest rate differential, processes which are nonlinear and heteroscedastic (having both variable drift and variable instantaneous standard deviation). Still, the model gives very precise predictions on both the asymptotic and instantaneous probability distributions of these two variables, predictions that should be easy to test. One prediction is that the asymptotic variability of the exchange rate should exceed that of a uniformly distributed random variable on the same band. Another is that the asymptotic distribution of the interest rate differential should be flat for small bands, and peaked for large bands. With regard to the instantaneous distributions, in the middle of the band the exchange rate's instantaneous standard deviation should be at its 
maximum and the interest rate differential's instantaneous standard deviation should be at its minimum. The reverse should be the case at the edges of the band.

A narrow target zone differs from a completely fixed exchange rate in that the interest rate differential's instantaneous standard deviation is high and even increasing when the zone narrows further. Hence there may be considerable uncertainty in the short-term interest rate, whereas there will be much less uncertainty in longer term interest rate. The precise implications of this for the term structure of interest rates in a target zone, and the practical importance of the formal difference between a narrow target zone and a completely fixed exchange rate will be the subject of further research.

The simplest model of the target zone assumes uncovered interest rate parity, that is, a zero exchange rate risk premium. An endogenous risk premium can be incorporated, but for small bands it ends up being too small to matter, and for large bands it only matters for the interest rate differential, but hardly for the exchange rate function.

An imperfectly credible band in the form of a devaluation risk is easily incorporated. and results in both a higher exchange rate and a higher interest rate differential.

There are ofvious problems and limitations with this target zone model, problems and limitations that warrant extensions and modification. One problem is that the stochastic: process assumed for the fundamental is exceedingly simple, with constant drift and standard deviation inside the band. The theory assumes that interventions occur only at the margins of the band, whereas intramarginal interventions are quite common in real world target zones. Such interventions would presumably lead to a fundamental process with variable drift. A technical problem here is that it is difficult to solve for the exchange rate with more complicated fundamental processes. Numerical solutions are easy to compute, though. ${ }^{21}$

21 A fundamental following a simple linear autoregressive process gives rise to an exchange rate which is described by the so called confluent hypergeometric function (cf. Dumas (1988a) and Froot and Obstfeld (1989b)), but other cases do not have analytic solutions, as far as I know. Miller and Weller (1989) show that some qualitative properties of the exchange rate solution can be examined for more general fundamental 
The model presented also assumes that the interventions are infinitesimal. Flood and Garber (1989) have extended the framework to include finite interventions. It is easy to infer the instantaneous distributions of the exchange rate and interest rate differential in their framework, but it remains to be seen what the implications for the asymptotic distributions are. ${ }^{22}$

processes, even if an explicit solution cannot be found.

22 Guiseppe Bertola has shown me some preliminary simulations of the exchange rate distribution with finite interventions. The asymptotic distribution of a regulated Brownian motion with jump controls has been derived in unpublished research notes by Bertola and Ricardo Caballero. 


\section{$\underline{\text { References }}$}

Buiter, Willem H., and Vittorio U. Grilli (1989), "The 'Gold Standard Paradox' and Its Resolution," Working Paper, Yale University.

Dixit, Avinash (1989a), "Analytical Approximations in Models of Hysteresis," Working Paper, Princeton University.

Dixit, Avinash (1989b), "A Simplified Exposition of the Theory of Optimal Control of Brownian Motion," Working Paper, Princeton University.

Dooley, Michael P., and Peter Isard (1983), "The Portfolio-Balance Model of Exchange Rates and Some Structural Estimates of the Risk Premium," IMF Staff Papers 30, $683-702$.

Dumas, Bernard (1988a), "Perishable Investment and Hysteresis in Capital Formation," Working Paper, University of Pennsylvania.

Dumas, Bernard (1988b), "Super Contact and Related Optimality Conditions: A

Supplement to Avinash Dixit's 'A Simplified Exposition of Some Results Concerning Regulated Prownian Motion'," Working Paper, University of Pennsylvania.

Dumas, Bernard (1989), "Pricing Physical Assets Internationally: A Non Linear

Heteroskedastic Process for Equilibrium Real Exchange Rates," Working Paper, University of Pennsylvania.

Flood, Robert E., and Peter M. Garber (1989), "The Linkage Between Speculative Attack and Target Zone Models of Exchange Rates," Working Paper No. 2918. National Bureau of Economic Research.

Frankel, Jeffrey A. (1982), "In Search of the Exchange Risk Premium: A Six-Currency Test Assuming Mean-Variance Optimization," Journal of International Money and Finance 49, 379-93.

Frankel, Jeffrey A. (1986), "The Implications of Mean-Variance Optimization for Four Questions in International Macroeconomics," Journal of International Money and 
Finance 5, S53-75.

Frankel, Jeffrey A. (1988), "Recent Estimates of Time-Variation on the Conditional Variance and in the Exchange Risk Premium," Journal of International Money and Finance 7, 115-125.

Froot, Kenneth A., and Maurice Obstfeld (1989a), "Exchange-Rate Dynamics Under Stochastic Regime Shifts: A Unified Approach," Working Paper.

Froot, Kenneth A., and Maurice Obstfeld (1989b), "Stochastic Process Switching: Sone Simple Solutions," Working Paper No. 2998, National Bureau of Economic Research. Harrison, J. Michael (1985), Brownian Motion and Stochastic Flow Systems, New York: John Wiley \& Sons.

Hörngren, Lars, and Anders Vredin (1988a), "The Foreign Exchange Risk Premium in d Currency Basket System," Chapter 4 in Vredin (1988).

Hörngren, Lars, and Anders Vredin (1988b), "The Foreign Exchange Risk Premium:

A Review of Theory and Evidence," Chapter 3 in Vredin (1988).

Klein, Michael W., (1989a), "Big Effects of Small Interventions: The Informational Roin of Intervention in Exchange Rate Policy," Working Paper, Clark University.

Klein, Michael W., (1989b), "Playing with the Band: Dynamic Effects of Target Zones in an Open Economy," Working Paper, Clark University.

Krugman, Paul (1988), "Target Zones and Exchange Rate Dynamics," Working Paper No. 2481, National Bureau of Economic Research.

Krugman, Paul (1989), "Target Zones with Limited Reserves," Working Paper, M.I.T. Miller, Marcus, and Paul Weller (1988), "Target Zones, Currency Options and Monetary Policy," Working Paper, University of Warwick.

Miller, Marcus, and Paul Weller (1989a), "Exchange Rate Bands and Realignments in Stationary Stochastic Setting," Working Paper No. 299, Centre for Economic Policy Research.

Miller, Marcus, and Paul Weller (1989b), "Solving Stochastic Saddlepoint Systems: A 
Qualitative Treatment with Economic Applications," Working Paper No. 308. Centre for Economic Policy Research.

Smith, Gregor W. (1989), "Solution to a Problem of Stochastic Process Switching," Working Paper.

Vredin, Anders (1988), Macroeconomic Policies and The Balance of Payments, Stockholm: Stockholm School of Economics.

Yeager, Leland B. (1976), International Monetary Relations: Theory, History and Policy. Second Edition, New York: Harper \& Row. 

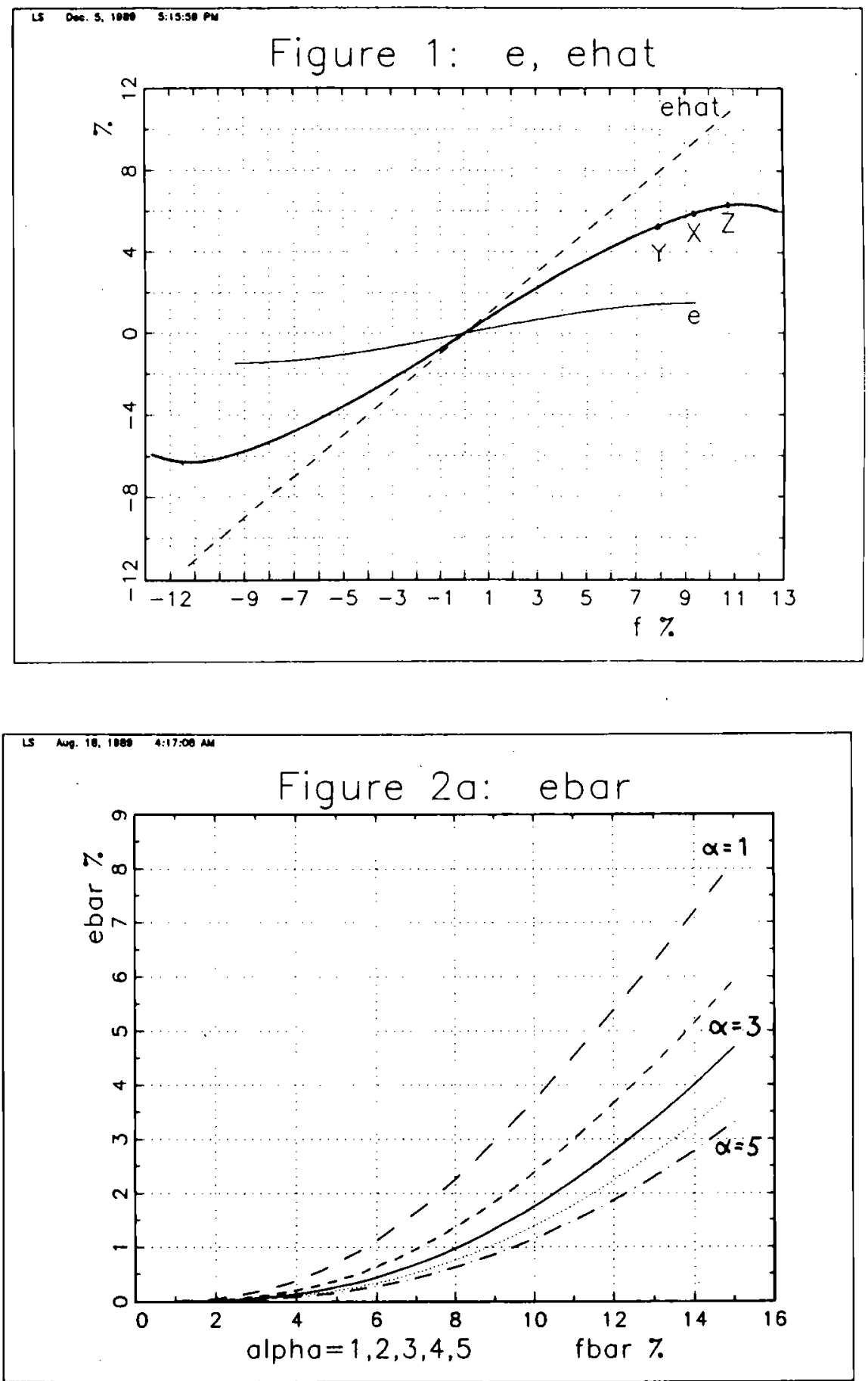

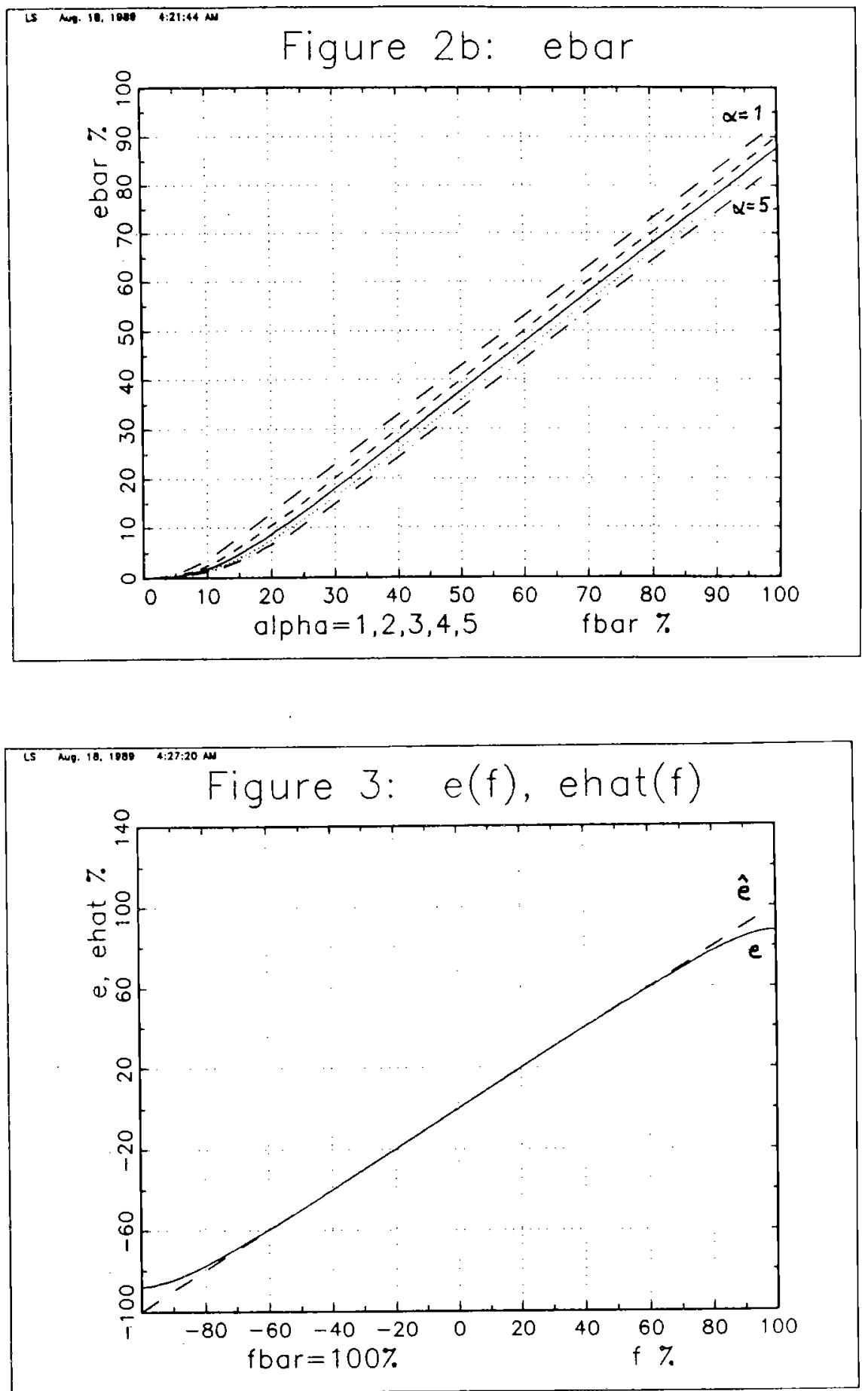

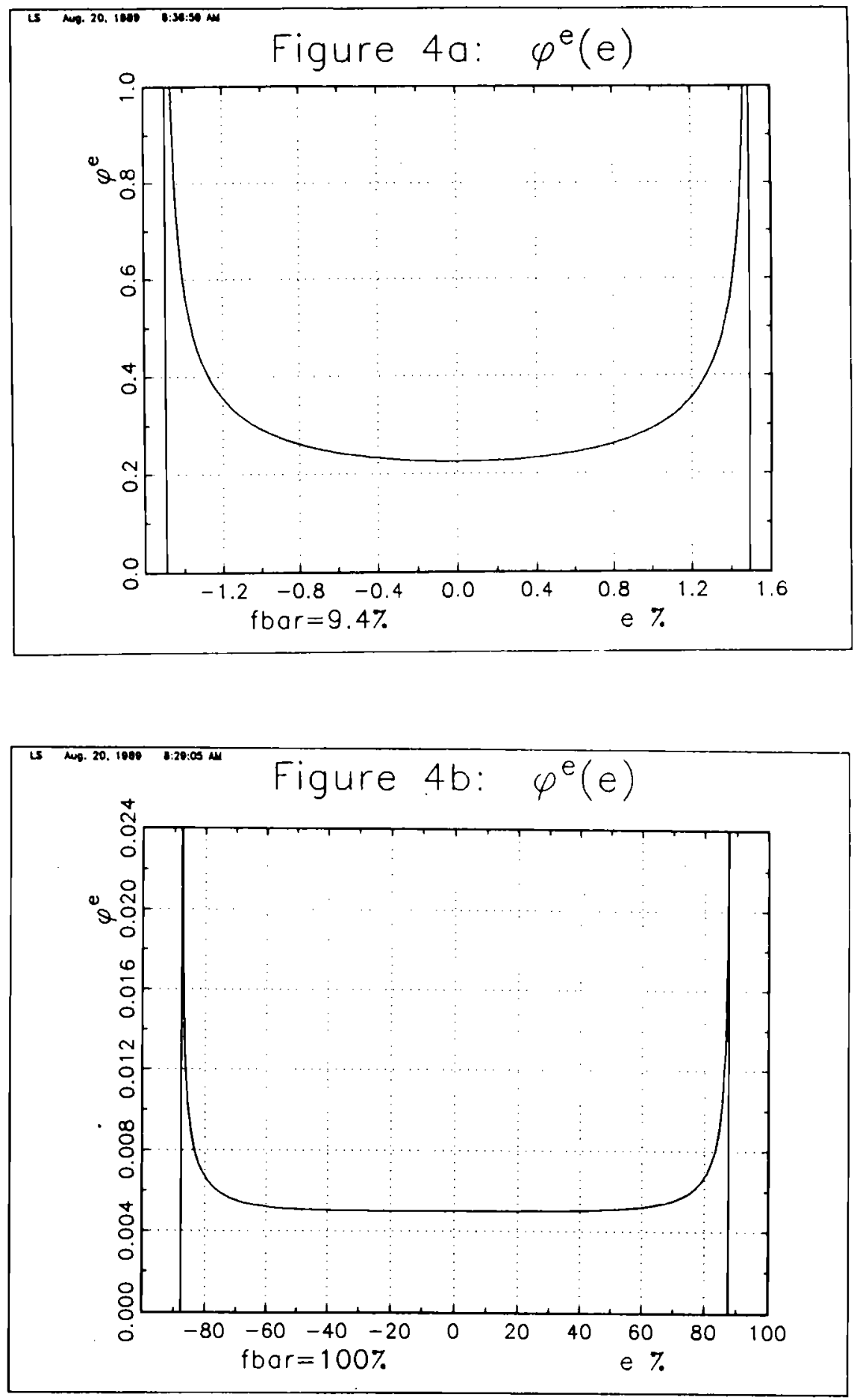

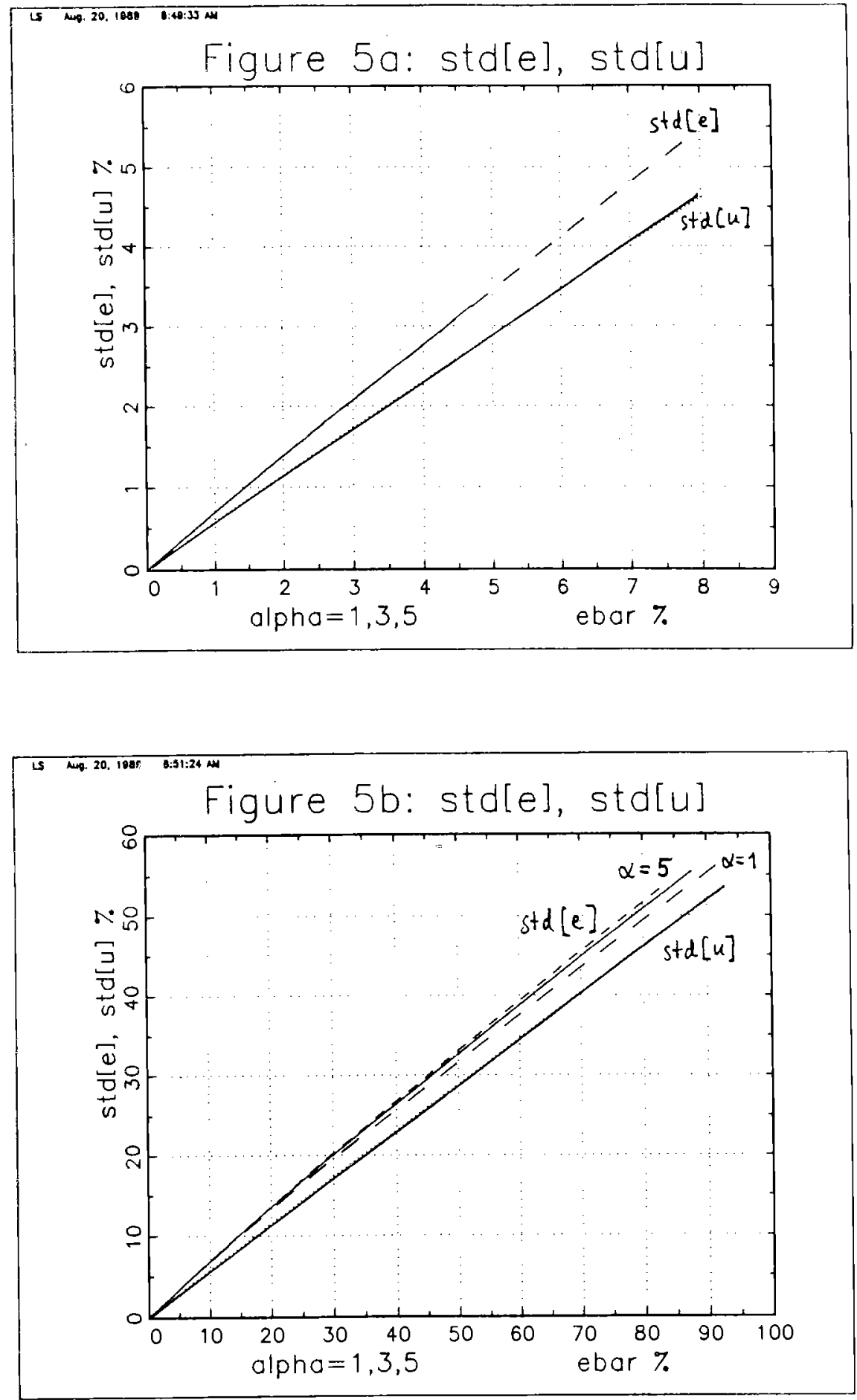

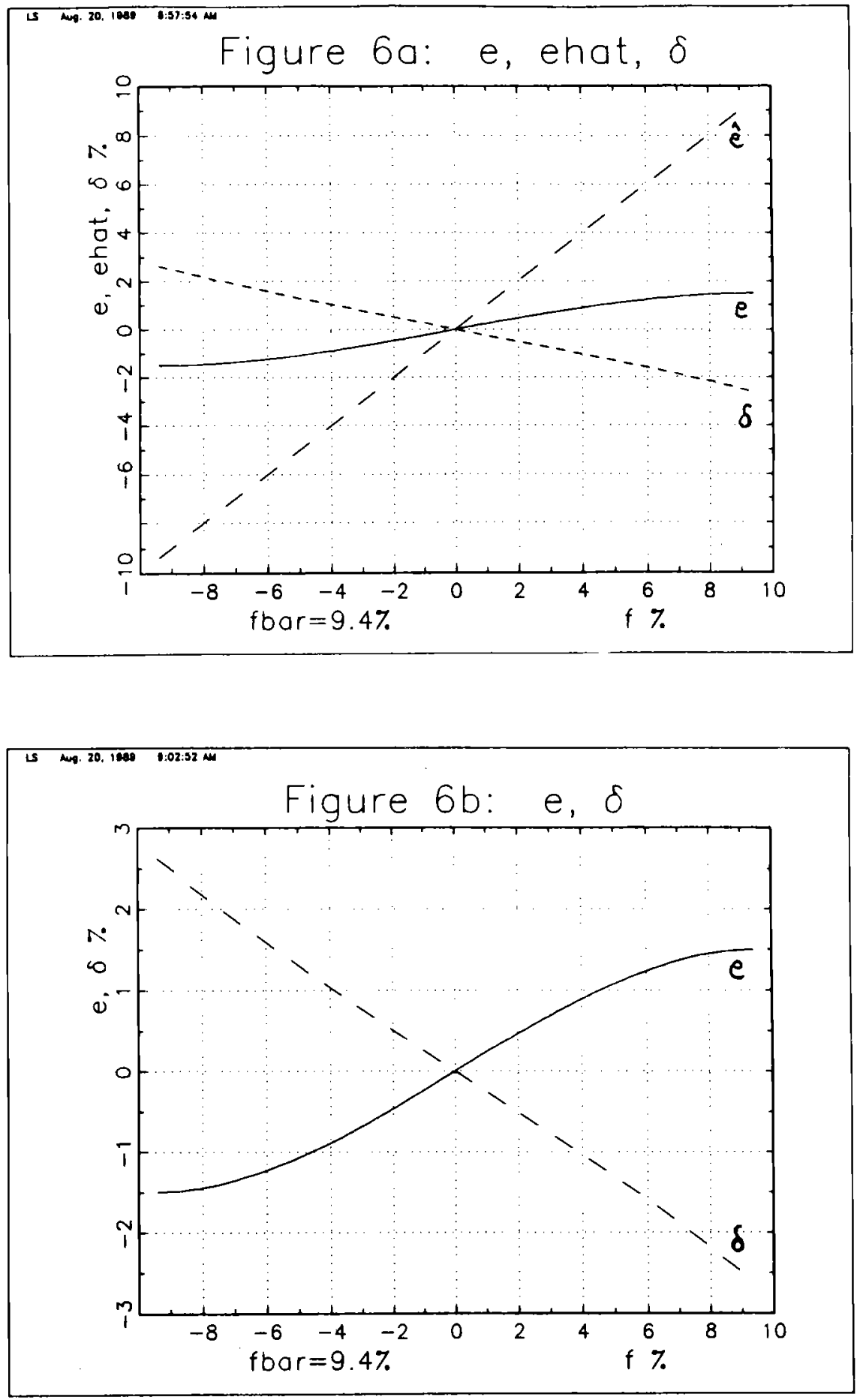

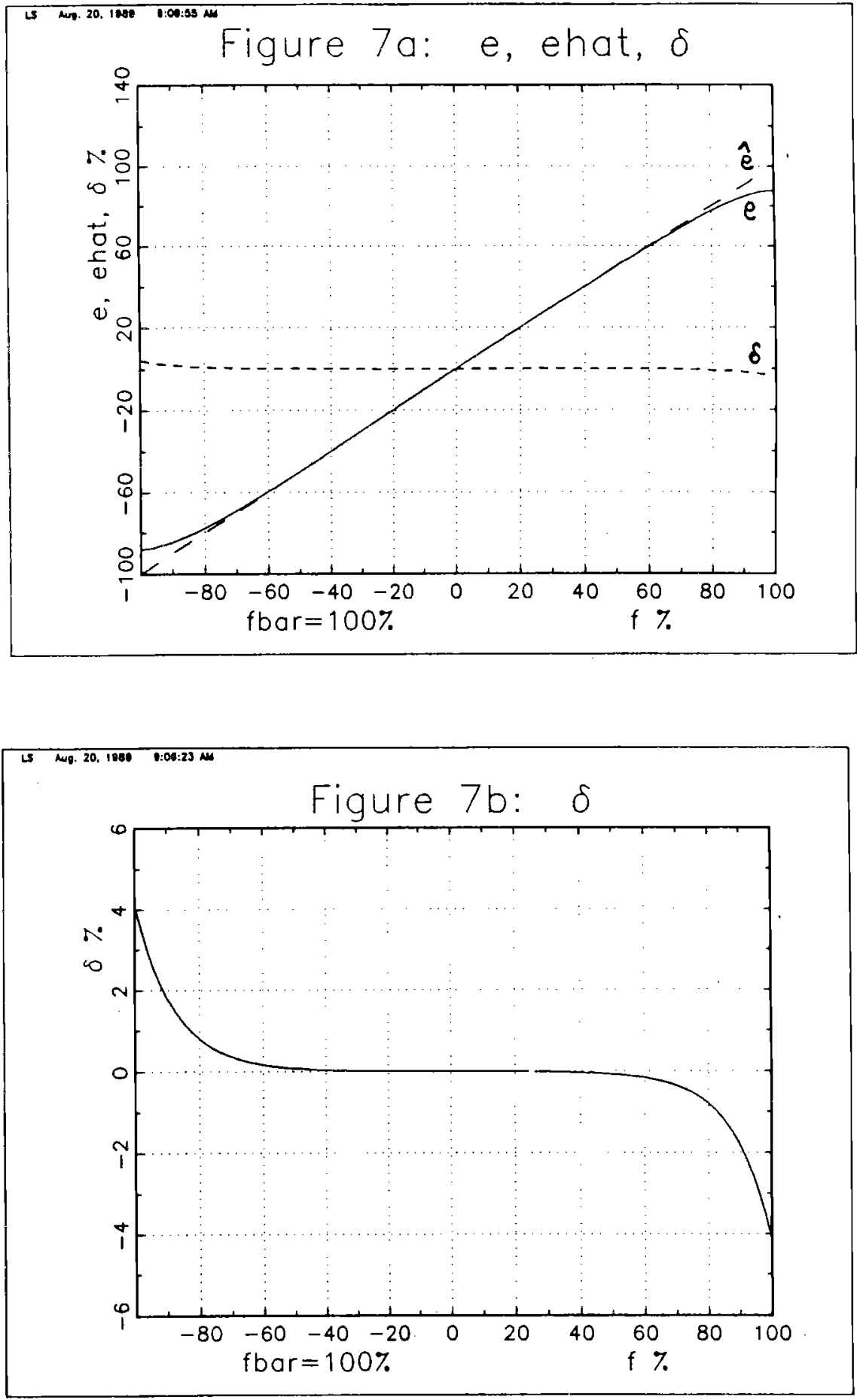

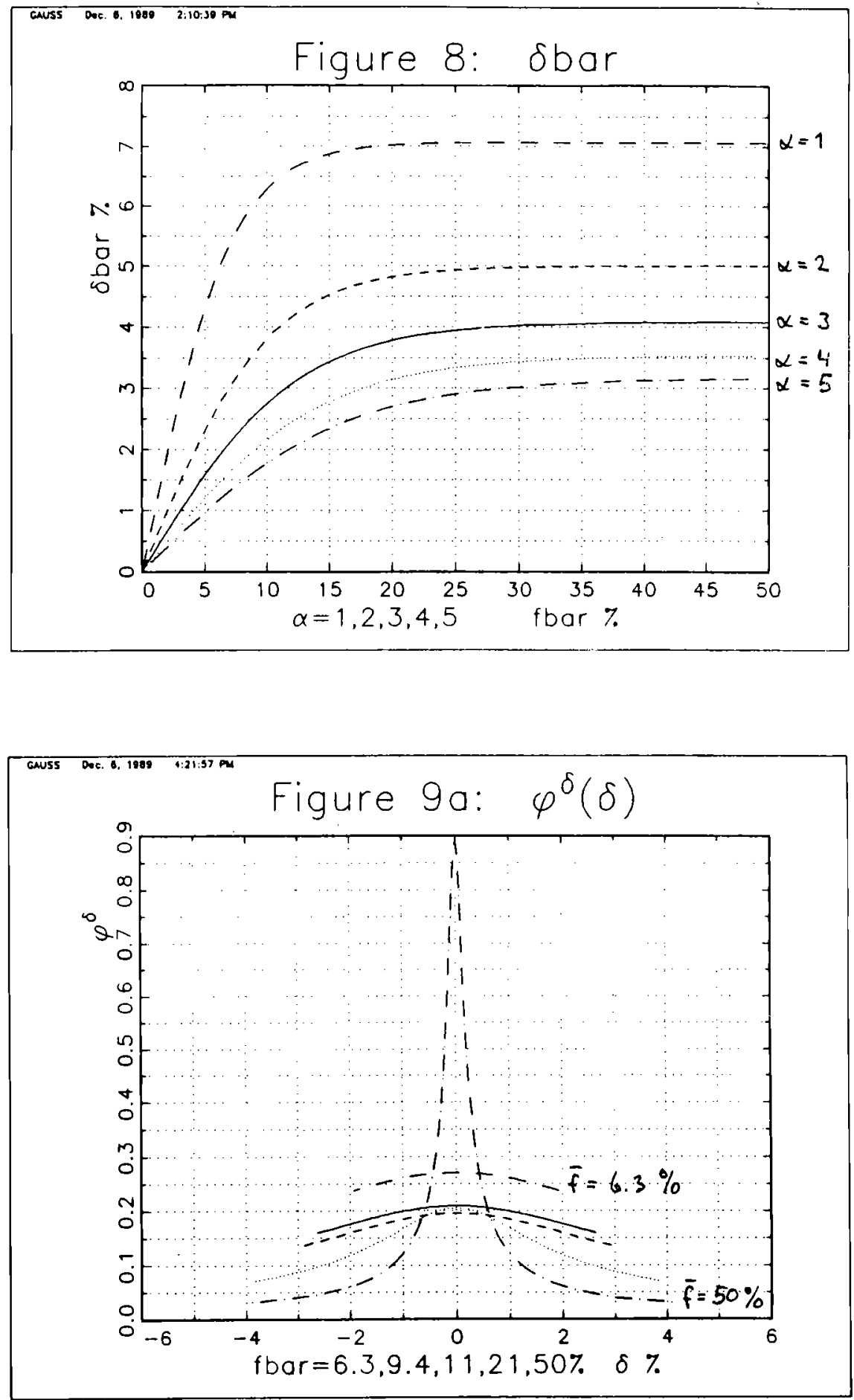

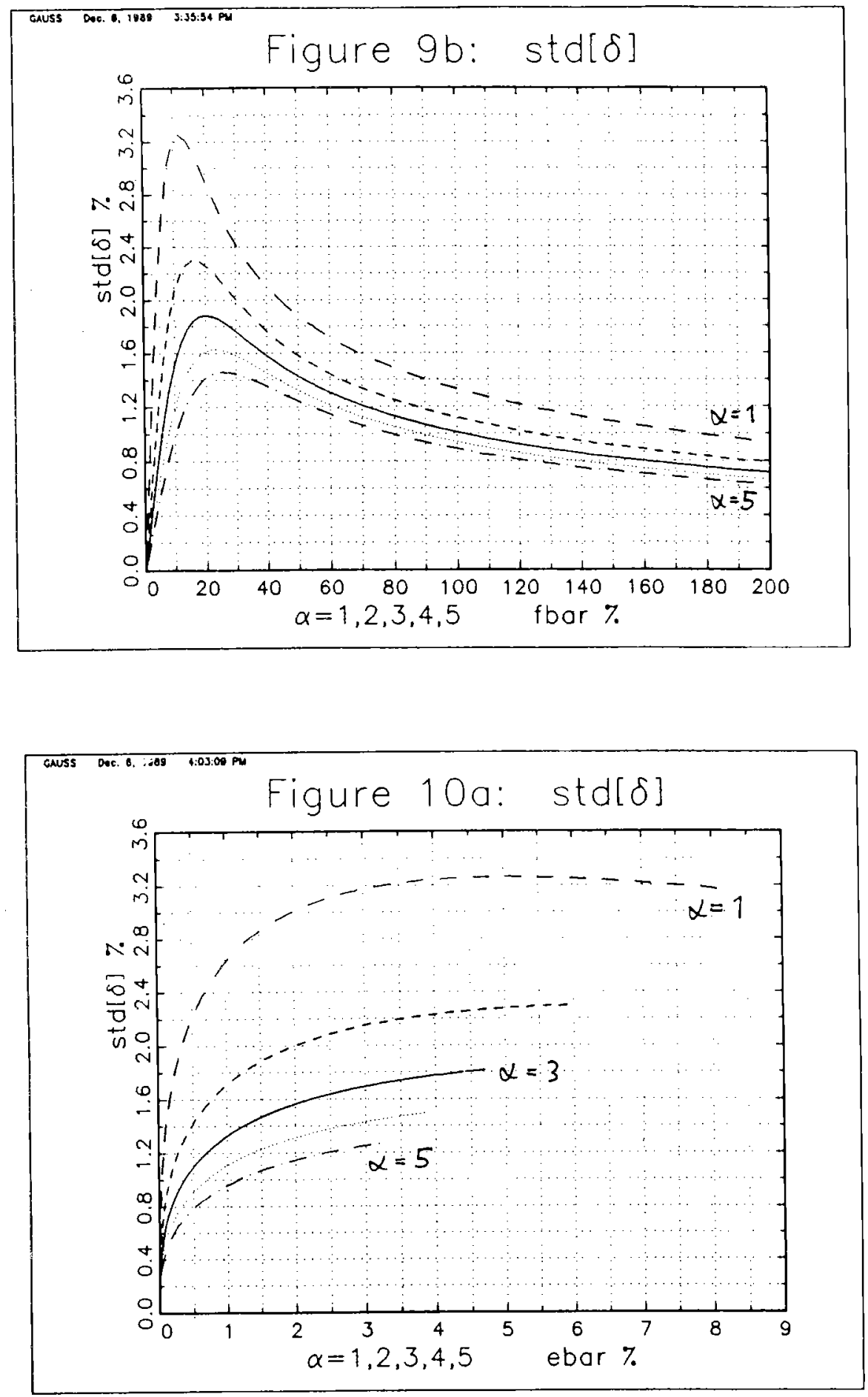

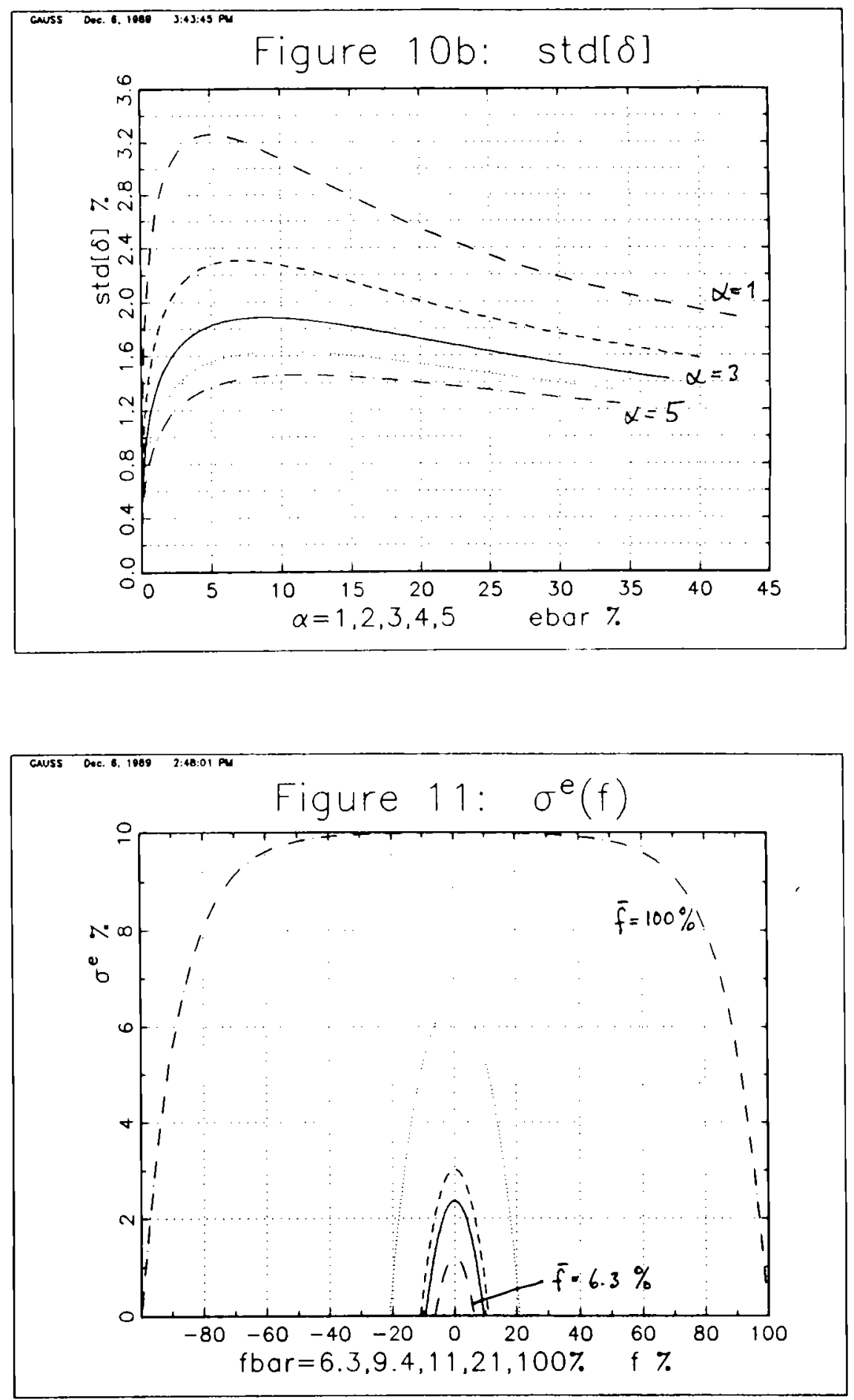

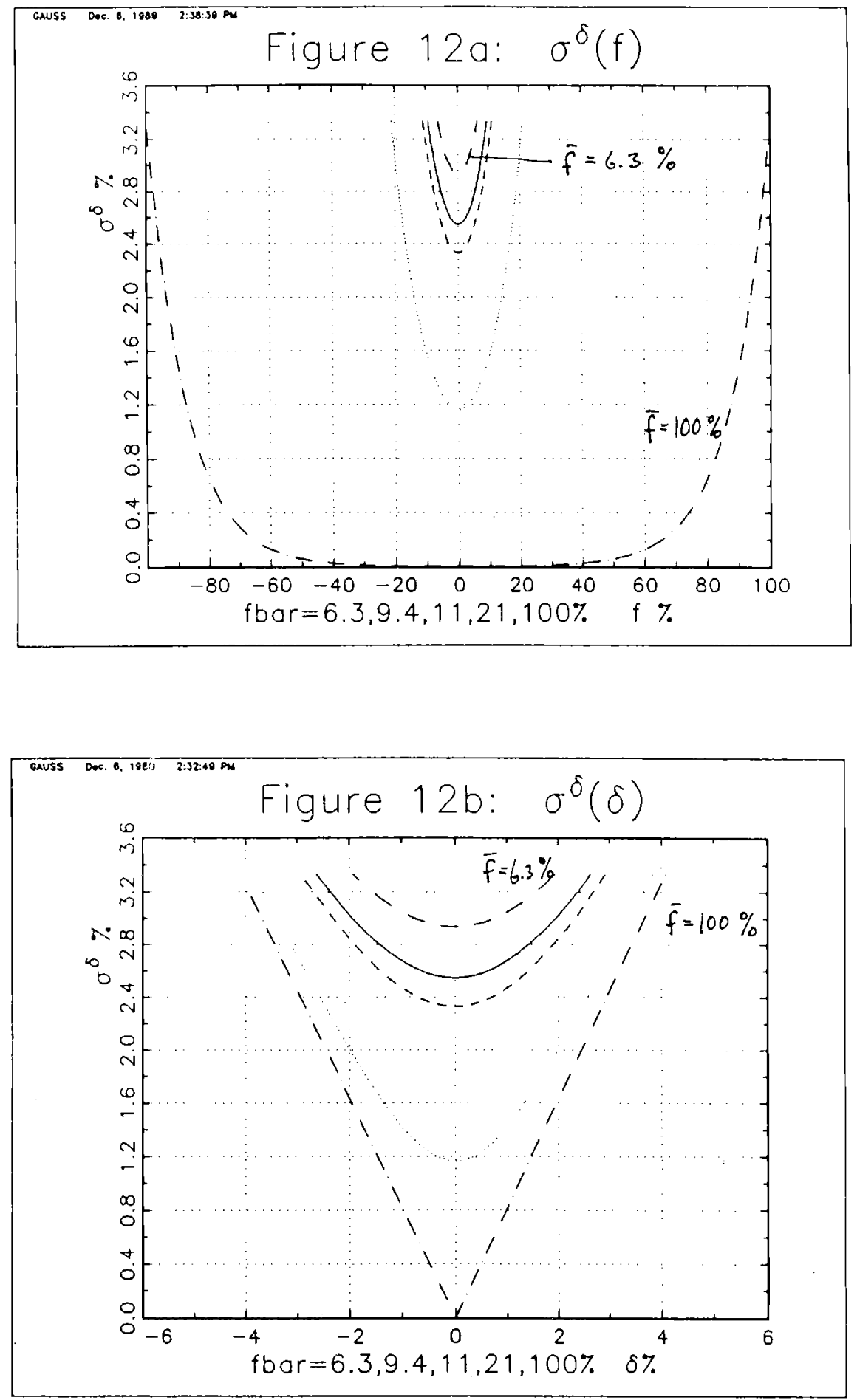